\title{
A morbidity study of viscose rayon workers exposed to carbon disulphide
}

\author{
H SAKURAI \\ From the Department of Preventive Medicine and Public Health, Keio University School of Medicine, \\ Tokyo, Japan
}

ABSTRACT A historical cohort study of the morbidity of $\mathrm{CS}_{2}$ and control workers was carried out in a viscose rayon factory and an adjacent cotton mill. A total of 725 male workers was employed at the two factories on 1 May 1966. All records of medical treatment received by these men from general practitioners, hospitals, and plant clinics for the period from 1 May 1966 to 31 December 1970 were obtained from receipts issued by those medical institutions and kept in the health insurance office. The study population was divided into five categories according to the duration and severity of $\mathrm{CS}_{2}$ exposure. Mean ages were found to be almost the same for all five groups (range of means 38.1-39.0 years). Period prevalence rates of cerebral vascular disease, ischaemic heart disease, hypertensive disease, diabetes mellitus, nephritis and nephrosis, mental disorders, and neurological diseases were calculated for all groups. Renal disease and hypertensive disease were significantly more prevalent in the rayon spinners and cutters with exposure histories of 10 years or more, the most highly exposed group, than in the non- $\mathrm{CS}_{2}$ workers. When the non-CS $\mathrm{C}_{2}$ workers and the $\mathrm{CS}_{2}$ workers with negligible exposure are combined and taken as a reference group, ischaemic heart disease was significantly more prevalent in the most highly exposed group than in the reference group. Ratios of period prevalence rates between these two groups were $7 \cdot 6$ for nephritis and nephrosis, $2 \cdot 3$ for ischaemic heart disease, and 1.9 for hypertensive disease. The ratios for cerebrovascular disease, diabetes mellitus, and neurological diseases were larger than $1 \cdot 0$, but the differences were not statistically significant.

Carbon disulphide $\left(\mathrm{CS}_{2}\right)$ has caused various types of intoxication throughout its history of use in vulcanisation shops and in the viscose rayon industry. ${ }^{1}$ Chronic vascular diseases, such as atherosclerosis of cerebral arteries, ${ }^{2}$ ischaemic heart disease, ${ }^{3}{ }^{4}$ nephrosclerosis similar to diabetic nephropathy, ${ }^{5-7}$ and retinal microaneurysms, ${ }^{78}$ have occurred after longterm exposure to $\mathrm{CS}_{2}$. The factors responsible for determining what type of diseases will actually occur in an exposed population are virtually unknown, except that the degree and duration of exposure to $\mathrm{CS}_{2}$ is assumed to play an important part. Yamagata et $a^{6}{ }^{7}$ reported 17 cases of $\mathrm{CS}_{2}$ nephrosclerosis found in nine Japanese viscose rayon plants. All the cases manifested overt proteinuria, but the diagnoses were made histopathologically on needle biopsy specimens. Based on these histological findings and

Received 2 February 1981

Accepted 2 March 1981 on the absence of clinical and laboratory signs suggestive either of cerebral arteriosclerosis and diabetes mellitus, Yamagata et al concluded that nephrosclerosis can be induced by $\mathrm{CS}_{2}$ as a type of primary chronic intoxication. Other reports from Japan $^{8-11}$ have found a high prevalence of nephropathy in several viscose rayon factories. In other countries, however, $\mathrm{CS}_{2}$ nephropathy has been generally regarded as an indication of a generalised atherosclerotic process induced by $\mathrm{CS}_{2} .{ }^{12}$ Thus the WHO Task Group on Environmental Health Criteria for Carbon Disulfide ${ }^{12}$ considers that renal involvement represents a very late consequence of heavy, protracted exposure to $\mathrm{CS}_{2}$.

The present study was undertaken because a unique opportunity was afforded to analyse a complete set of records of the medical treatment given to all employees of a Japanese viscose rayon factory during a period of about five years from 1966 to 1970 . In view of the diversity of organs reported 
Table 1 Age distribution of the total male work force

\begin{tabular}{ccccccc}
\hline & 519 & $20-$ & $30-$ & $40-$ & $\geqslant 50$ & Total \\
\hline No of subjects & 10 & 53 & 383 & 247 & 32 & 725 \\
\hline
\end{tabular}

to be affected by long-term exposure to $\mathrm{CS}_{2}$, the purpose of this study was to provide epidemiological evidence not only on the presence of $\mathrm{CS}_{2}$-induced chronic vasculopathies but also on the relative importances of these different types of toxic effects in a population of Japanese workers.

\section{Material and methods}

The material for the study comprised the records of medical care given to the employees of a rayon staple plant and a neighbouring spinning mill during 56 months from 1 May 1966 to 31 December 1970. The material was obtained by the Japan Chemical Fibres Association in 1971 and had been kept for the analysis. Both factories, located in a local city, were the branch factories of a spinning and artificial fibres manufacturing company.

The records of treatments consisted of receipts issued from all medical institutions including general practitioners, hospitals, and plant clinics to the health insurance office that served the two factories during the observation period. In conformity with health insurance law the receipts provided information on clinical diagnoses and medical treatments given to patients. All the diagnoses consistent with cerebrovascular disease (codes 431-438, excluding subarachnoid haemorrhage, code 430), ischaemic heart disease (codes 410-414), hypertensive disease (codes 400-404), diabetes mellitus (code 250), nephritis and nephrosis (codes 580-584), mental disorders (codes 290-299, 300-309), and neurological diseases (codes 330-337, 340-349, 350-359) were enumerated according to the International Classification of Diseases. When a worker had been treated for one of those diseases, he was determined as a case of that disease. Even if a worker had been treated repeatedly, and that was the case in almost all instances, he was enumerated only as a single case.

Table 1 shows the age distribution of all the male employees in the two factories on 1 May 1966. The number of employees whose ages were under 30 years, or 50 or over, was relatively small. Since the $\mathrm{CS}_{2}$-exposed and non-exposed subjects were found to be disproportionately distributed in these age groups, they were excluded from the analysis.

Status of exposure to $\mathrm{CS}_{2}$ before the beginning of the observation period was determined on the basis of individual job records kept by the firm.

Table 2 shows the distribution of the study population of 630 men by duration and degree of exposure to $\mathrm{CS}_{2}$. Non- $\mathrm{CS}_{2}$ workers consisted mainly of cotton spinners and clerical workers. The workers who had been engaged in rayon spinning, cutting, and the first step of washing (groups $\mathrm{CS}_{2}-3, \mathrm{CS}_{2}-4$ ) were considered to be a highly exposed population; the other $\mathbf{C S}_{2}$ workers such as viscose makers, finishers, and maintenance workers (groups $\mathrm{CS}_{2}-1$, $\mathrm{CS}_{2}$-2) were considered to be less exposed. When a person had worked in a highly exposed job (as a rayon spinner, for example) even for under a year, he was classified as "highly exposed" regardless of what other jobs he may have done. As a result, groups $\mathrm{CS}_{2}-1$ and $\mathrm{CS}_{2}-2$ included neither spinners nor other highly exposed workers. Similarly, the non- $\mathrm{CS}_{2}$ workers included no $\mathrm{CS}_{2}$ workers, not even those with very short exposure. Exposure to $\mathbf{C S}_{2}$ after the beginning of the observation period was neglected. This strategy of classification was based on the fact that the concentrations of $\mathbf{C S}_{2}$ had been appreciably higher in the rayon spinning and cutting areas than elsewhere, and also that the working environment of this factory had been remarkably improved a few years before the beginning of the observation period. This latter fact may justify the neglect of comparatively low-grade exposure during the observation period.

Duration of exposure to $\mathrm{CS}_{2}$ was defined as the sum of the number of months spent in those areas where $\mathrm{CS}_{2}$ was used. It was divided into two levels,

Table 2 Study population classified by duration and degree of exposure to $\mathrm{CS}_{2}$

\begin{tabular}{|c|c|c|c|c|c|}
\hline \multirow[t]{2}{*}{ Group } & \multirow[t]{2}{*}{ Level of exposure } & \multirow{2}{*}{$\begin{array}{l}\text { Duration of exposure } \\
(y r)\end{array}$} & \multirow[t]{2}{*}{ No of subjects } & \multicolumn{2}{|c|}{ Age $(y r)$} \\
\hline & & & & Mean & $S D$ \\
\hline $\begin{array}{l}\text { Non-CS } \\
C_{2}-1 \\
C_{2} S_{4-2} \\
C S_{2-3} \\
C_{2}-4 \\
\text { Total }\end{array}$ & $\begin{array}{l}0 \\
\text { Lower* } \\
\text { Lower } \\
\text { Higher } † \\
\text { Higher }\end{array}$ & $\begin{array}{r}0 \\
<10 \\
\geqslant 10 \\
<10 \\
\geqslant 10\end{array}$ & $\begin{array}{r}276 \\
79 \\
40 \\
161 \\
74 \\
630\end{array}$ & $\begin{array}{l}39 \cdot 0 \\
39 \cdot 0 \\
38 \cdot 9 \\
38 \cdot 1 \\
38 \cdot 8 \\
38 \cdot 7\end{array}$ & $\begin{array}{l}5 \cdot 6 \\
5 \cdot 4 \\
5 \cdot 7 \\
5 \cdot 0 \\
4 \cdot 8 \\
5 \cdot 3\end{array}$ \\
\hline
\end{tabular}

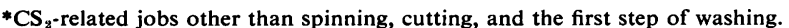

†Spinning, cutting, and the first step of washing. 
Table 3 Period prevalence rates of several chronic diseases in the study population. (Numbers in parentheses are period prevalence rates in percentages calculated from the population at risk and the number of cases)

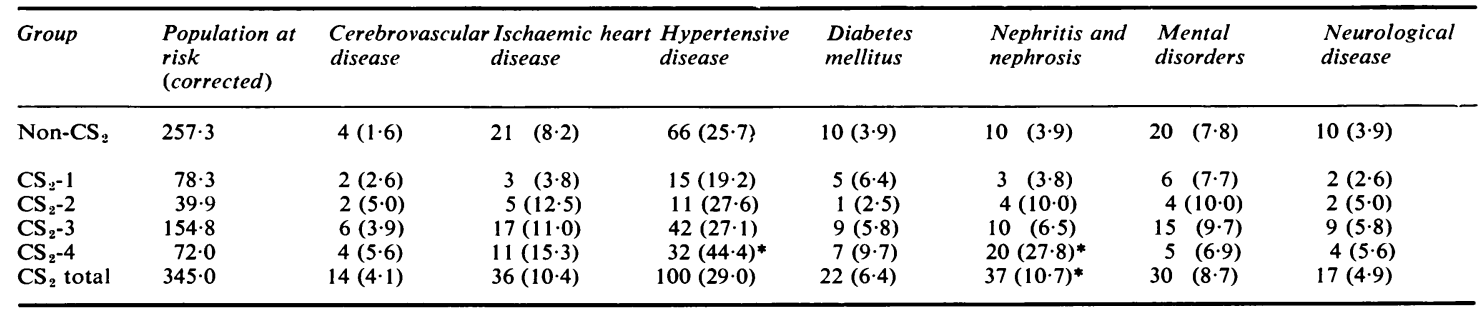

${ }^{*} \mathrm{p}<0.001$, tested by chi-square method for the difference from the non-CS $\mathrm{Sroup}_{2}$

under 10 years and 10 years or more. Table 2 shows the number of workers in each exposure group and their mean ages. A remarkable feature of this table is that the mean ages and standard deviations turned out to be almost the same for all five groups. To minimise observer bias, the degree of exposure to $\mathrm{CS}_{2}$ was assessed independently of the extraction of the medical histories. These tasks were performed blind, the former by several clerks of the department of industrial health of the Japan Chemical Fibres Association, the latter by me.

\section{Results}

Period prevalence rates for several chronic diseases in non- $\mathrm{CS}_{2}$ and $\mathrm{CS}_{2}$ workers are shown in table 3. The number of the population at risk was corrected for any uncompleted observation on the basis of actually observed numbers of months. Fifty-four workers $(8 \cdot 6 \%)$ could not be followed up throughout the study period because of retirement, transfer to other plants, or death not related to this study, and the total population at risk was consequently reduced from 630 to $602 \cdot 3$.

The prevalence rates for most diseases are manifestly larger in the most highly exposed groupnamely, in rayon spinning and cutting workers with over 10 years' exposure-compared with non- $\mathrm{CS}_{2}$ workers. Hypertensive disease and nephritis and nephrosis were significantly more prevalent in spinning and cutting workers. Cerebrovascular disease, ischaemic heart disease, and diabetes mellitus also appeared to be more prevalent in the most exposed group, but the differences were not statistically significant. For mental disorders and neurological diseases no difference was found between the groups. A comparison between three rearranged groups of workers is listed in table 4 . Chronic $\mathrm{CS}_{2}$ poisoning in the form of vasculopathy has been recognised since about 1960 in Japan ${ }^{9}-$ that is, about six years before the start of this study period-and so many $\mathrm{CS}_{2}$ workers had been transferred to non-CS $\mathbf{C S}_{2}$ jobs in this factory and selected healthy workers had been newly allocated to $\mathrm{CS}_{2}$ jobs by 1966 . This action obviously tended to make the workers in the group $\mathrm{CS}_{2}-1$ a selected healthier population who were, moreoever, exposed to only slight concentrations of $\mathrm{CS}_{2}$ for a relatively short time. Workers who were known to have chronic vascular disease were retained in the non-CS $\mathrm{C}_{2}$ jobs to avoid the vasotoxic effects of $\mathrm{CS}_{2}$. For these reasons, the non-CS $\mathrm{CS}_{2}$ workers combined with $\mathrm{CS}_{2}-1$ workers are considered to be a better reference group than the non- $\mathrm{CS}_{2}$ group alone, and $\mathrm{CS}_{2}-2$ combined with $\mathrm{CS}_{2}-3$ are considered to be an intermediate exposed population.

Table 4 Period prevalence rates and risk ratios of several chronic diseases in subgroups of workers

\begin{tabular}{|c|c|c|c|c|c|c|c|c|c|c|c|c|c|c|c|}
\hline \multirow[t]{2}{*}{ Group } & \multirow{2}{*}{$\begin{array}{l}\text { Population } \\
\text { at risk } \\
\text { (corrected) }\end{array}$} & \multicolumn{2}{|c|}{$\begin{array}{l}\text { Cerebrovascular } \\
\text { disease }\end{array}$} & \multicolumn{2}{|c|}{$\begin{array}{l}\text { Ischaemic heart } \\
\text { disease }\end{array}$} & \multicolumn{2}{|c|}{$\begin{array}{l}\text { Hypertensive } \\
\text { disease }\end{array}$} & \multicolumn{2}{|c|}{$\begin{array}{l}\text { Diabetes } \\
\text { mellitus }\end{array}$} & \multicolumn{2}{|c|}{$\begin{array}{l}\text { Nephritis and } \\
\text { nephrosis }\end{array}$} & \multicolumn{2}{|c|}{ Mental disorders } & \multicolumn{2}{|c|}{$\begin{array}{l}\text { Neurological } \\
\text { disease }\end{array}$} \\
\hline & & $P$ & $R R$ & $P$ & $R R$ & $P$ & $R R$ & $P$ & $R R$ & $P$ & $R R$ & $P$ & $R R$ & $P$ & $R R$ \\
\hline $\begin{array}{l}\text { Non-CS } \mathrm{CS}_{2} \text { and } \\
\mathrm{CS}_{2-1}\end{array}$ & $335 \cdot 6$ & $\begin{array}{l}6 \\
(1 \cdot 8)\end{array}$ & $1 \cdot 0$ & $\begin{array}{l}24 \\
(7 \cdot 2)\end{array}$ & $1 \cdot 0$ & $\begin{array}{l}81 \\
(24 \cdot 1)\end{array}$ & $1 \cdot 0$ & $\begin{array}{l}15 \\
(4 \cdot 5)\end{array}$ & $1 \cdot 0$ & $\begin{array}{l}13 \\
(3 \cdot 9)\end{array}$ & $1 \cdot 0$ & $\begin{array}{l}26 \\
(7 \cdot 7)\end{array}$ & $1 \cdot 0$ & $\begin{array}{l}12 \\
(3 \cdot 6)\end{array}$ & $1 \cdot 0$ \\
\hline $\begin{array}{c}\mathrm{CS}_{2}-2 \text { and } \\
\mathrm{CS}_{2,-3}\end{array}$ & $194 \cdot 7$ & $\begin{array}{l}8 \\
(4 \cdot 2)\end{array}$ & $2 \cdot 3$ & $\begin{array}{l}21 \\
(11 \cdot 0)\end{array}$ & $1 \cdot 5$ & $\begin{array}{l}52 \\
(27 \cdot 3)\end{array}$ & $1 \cdot 1$ & $\begin{array}{l}10 \\
(5 \cdot 2)\end{array}$ & $1 \cdot 2$ & $\begin{array}{l}14 \\
(7 \cdot 3)\end{array}$ & 1.9 & $\begin{array}{l}19 \\
(10 \cdot 0)\end{array}$ & $1 \cdot 3$ & $\begin{array}{l}11 \\
(5 \cdot 8)\end{array}$ & $1 \cdot 6$ \\
\hline $\mathrm{CS}_{2,-4}$ & $72 \cdot 0$ & $\begin{array}{l}4 \\
(5 \cdot 9)\end{array}$ & $3 \cdot 3$ & $\begin{array}{l}11^{*} \\
(16 \cdot 2)\end{array}$ & $2 \cdot 3$ & $\begin{array}{c}32 \dagger \\
(47 \cdot 1)\end{array}$ & 1.9 & $\begin{array}{c}7 \\
(10 \cdot 3)\end{array}$ & $2 \cdot 3$ & $\begin{array}{c}20 \dagger \\
(29 \cdot 4)\end{array}$ & $7 \cdot 6$ & $\begin{array}{l}4 \\
(5 \cdot 9)\end{array}$ & 0.8 & $\begin{array}{l}4 \\
(5 \cdot 9)\end{array}$ & 1.6 \\
\hline
\end{tabular}

$\mathbf{P}=$ Period prevalence rate. (Number in parentheses indicates period prevalence rate in percentages.)

$\mathbf{R} R=\mathbf{R}$ isk ratio. Ratio of period prevalence rates with reference to the non-CS $\mathbf{C}_{2}$ group combined with $\mathbf{C S}_{2}-1$.

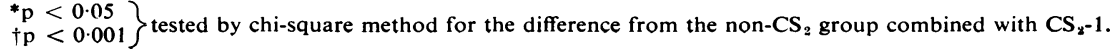


Table 4 lists the risk ratios, calculated as the ratio of each prevalence rate to that of the reference group. The risk ratios of the intermediate exposed workers were found to be consistently larger than 1.0; those of the most exposed workers were the largest for each disease category except mental disorders and neurological disease. Ischaemic heart disease, hypertensive disease, and renal diseases were significantly more prevalent in rayon spinning and cutting workers exposed for over 10 years. The apparent increase in the prevalence rates in the intermediate exposed group was not statistically significant.

\section{Discussion}

In this study it was found that several types of chronic vascular injuries were significantly more prevalent in the most highly exposed workers than in reference workers. As for the comparability of exposed and non-exposed worker groups, both were male, engaged predominantly in physical works, and well matched for age. The factories from which the study population was taken were located in a local city, the background of which was essentially agricultural, and its dwellers tended not to move. Hence, although other characteristics of the study population were not specified, $\mathrm{CS}_{2}$-exposed workers and their reference subjects are considered to have been reasonably similar with respect to such factors as place of birth and residence, level of income, and living habits.

It was necessary to use the period prevalence rate - that is, prevalence rate at the start of the observation period added to incidence rate during the same period-as the measure of morbidity because they could not be separated on the basis of available information. The period prevalence rate of a chronic disease, however, may be almost identical with its prevalence rate at the end of the observation period. It may even be close to the incidence rate for periods from the birth of the subjects to the end of the observation period. Therefore, for most of the disease categories in this study, the use of period prevalence rate is not considered to have induced any substantial error into the interpretation of the results.

The accuracy of diagnosis needs some comment. Reported diagnoses could not be confirmed by any other information in this study. Period prevalence rates for some of the observed diseases in table 3 appear somewhat higher, even in the non- $\mathrm{CS}_{2}$ workers, than would be expected from prevalence rates in the general population. This may be accounted for partly by the fact that period prevalence instead of either incidence or prevalence alone had to be used and partly by diagnostic bias by practising physicians. It is assumed, however, that most of the diagnoses were reasonably accurate for such highly prevalent chronic diseases as were handled in this study. Furthermore, the important point is the difference in period prevalence rates between groups of workers rather than the absolute values. Considering all these aspects, it may be concluded that $\mathrm{CS}_{2}$ caused several chronic vascular diseases in workers who had received severe exposure to this substance. It was also clearly shown that nephropathy and hypertension had been the predominant types of $\mathrm{CS}_{2}$-induced diseases in this study cohort.

Many types of $\mathrm{CS}_{2}$-induced vascular disorders in man have been documented from the clinical and pathological points of view. Relatively few wellcontrolled epidemiological studies have been reported as to the quantitative aspects of chronic $\mathrm{CS}_{2}$ vasculopathy. Tiller et $\mathrm{l}^{3}$ showed that the death rate from coronary heart disease in men with over 10 years' exposure in a British viscose rayon factory was 2.5 times that of other workers. The death rates from other cardiovascular diseases, including cerebrovascular disease, and from all other causes were also higher in $\mathbf{C S}_{\mathbf{2}}$ workers, but the differences were fewer than in the case of coronary heart disease and were not statistically significant. Hernberg et $a^{413-16}$ reported the results of a series of cohort mortality studies of $343 \mathrm{CS}_{2}$-exposed rayon workers and the same number of matched control workers from a paper mill. The study was started in 1967 and the five-year mortality from coronary heart disease in the cohort of workers exposed to about $10-30 \mathrm{ppm}$ $\mathrm{CS}_{2}$ was 4.67 times that of the control workers. The 10 -year mortality from coronary heart disease was 2.64 times higher than the control group, and other causes of death did not show any statistically significant differences between the two comparison groups. Mowé17 reported similar results from Norway, where a three-fold excess mortality from coronary heart disease was found among workers, aged 35-54 years, compared with unexposed workers in other departments. In all these epidemiological studies excess deaths from coronary heart disease were the most pronounced; renal disorders were not shown to be increased in $\mathbf{C S}_{2}$ workers. By contrast, the present study indicated that the risk ratio for renal diseases was by far the largest among the observed categories. Furthermore, it was found that the absolute increase in the period prevalence rate of renal diseases attributable to $\mathrm{CS}_{2}$ exposure was almost the same as that of hypertensive disease, and they were clearly larger than the absolute increases in other categories of disease. The reason for this apparent discrepancy cannot be positively inferred from the available information. It may be pertinent to note here that ischaemic heart disease was also significantly more prevalent, though to a less extent, 
in rayon spinning and cutting workers than in reference workers, as shown in table 4 . The risk ratio for ischaemic heart disease in this highly exposed sample was $2 \cdot 3$, a value reasonably consistent with the other epidemiological studies cited above. Considering the fact that both types of vasculopathy were found in the present cohort, while only ischaemic heart disease was significantly increased in populations of European workers, it may be assumed that a severe exposure favours the occurrence of renal disorders and a less severe chronic exposure gives rise mainly to coronary heart disease.

The past levels of exposure to $\mathrm{CS}_{2}$ of this study population are uncertain because no reliable exposure data could be obtained. My impression, and I had inspected the same factory several years before the start of the study period when the work room environment had not yet been improved, was that eight-hour average $\mathrm{CS}_{2}$ concentrations in the spinning and cutting area were unquestionably higher than $20 \mathrm{ppm}$, the threshold limit value at the time.

The increased prevalence of hypertension found in this study deserves some comment. In most papers that have reported cases of $\mathrm{CS}_{2}$-induced nephropathy, hypertension was also often observed and was mostly assumed to be nephrogenic. Similarly, about half the subjects in this study who were being treated for hypertension in the group $\mathrm{CS}_{2}-4$ were also being treated for renal disorders. Therefore, the increased prevalence of hypertension may have been mostly nephrogenic. The possibility remains, however, that some cases of hypertension had been caused primarily by $\mathrm{CS}_{2}$ because several papers ${ }^{41418}$ have reported a rise in blood pressure attributable to $\mathrm{CS}_{2}$ exposure in otherwise apparently healthy rayon workers.

The risk ratios for cerebrovascular disease were somewhat higher than 1.0 in $\mathrm{CS}_{2}$-exposed workers, but the differences were not statistically significant. Considering the small number of patients with cerebrovascular disease compared with those of renal or hypertensive diseases, it seems clear that cerebrovascular involvement was of only minor importance. Yamagata et $a l^{6} 7$ called attention to the fact that diffuse nephrosclerosis was found by needle biopsy in $\mathrm{CS}_{2}$ workers who did not show any sign of cerebrovascular injuries. Referring to several earlier papers ${ }^{2}{ }^{19-22}$ in which nephropathy in $\mathrm{CS}_{2}$ workers was accounted for by generalised atherosclerosis, Yamagata et al speculated that primary chronic $\mathrm{CS}_{2}$ nephropathy may be induced when the level of exposure is not so severe as to cause generalised atherosclerosis. The question naturally arises whether such differences in the type of vasculopathy prevailing in a given $\mathrm{CS}_{2}$-exposed population could be explained solely by the degree or duration, or both, of exposure. Could nutritional or ethnic factors play a prominent part in determining the natural history of chronic $\mathrm{CS}_{2}$ poisoning? More study is needed to elucidate the dose-effect relationships in workers with long-term exposure to concentrations lower than those in the present study.

I thank Dr J Kubota, Professor T Toyama, Professor G Goto, and the staff of the Japan Chemical Fibres Association for their valuable support throughout the study.

\section{References}

1 World Health Organisation. Environmental health criteria 10: carbon disulfide. Geneva: WHO, 1979:41-2.

2 Vigliani EC, Pernis B. Klinische und experimentelle Untersuchungen über die durch Schwefelkohlenstoffbedingte Atherosklerose. Archiv für Gewerbepathologie und Gewerbehygiene 1955;14:190-202.

${ }^{3}$ Tiller JR, Schilling RSF, Morris JN. Occupational toxic factor in mortality from coronary heart disease. $\mathrm{Br}$ Med J 1968 ;iv:407-11.

${ }^{4}$ Hernberg S, Partanen T, Nordman C-H, Sumari P. Coronary heart disease among workers exposed to carbon disulphide. Br J Ind Med 1970;27:313-25.

${ }^{5}$ Uehlinger E. Über die Schwefelkohlenstoff Glomerulosklerose. Schweiz Z Pathol Bakteriol 1952;15:217-24.

6 Yamagata Y, Yuda A, Suzuki K, et al. Carbon disulphide nephrosclerosis, with special reference to the similarity to diabetic glomerulosclerosis. I. Renal biopsy findings in 17 patients. Diabetes (Japan) 1966;9: 208-17. (In Japanese with English abstract.)

${ }^{7}$ Yamagata $\mathrm{Y}$, Nemoto $\mathrm{T}$, Takahashi $\mathrm{M}$, et al. Carbon disulphide nephrosclerosis, with special reference to the similarity to diabetic glomerulosclerosis. II. A clinicopathological study based on renal biopsy materials. Diabetes (Japan) 1966;9:218-25. (In Japanese with English abstract.)

${ }^{8}$ Goto S, Hotta R. The medical and hygienic prevention of carbon disulphide poisoning in Japan. In: Brieger $\mathbf{H}$, Teisinger $\mathrm{J}$, eds. Toxicology of carbon disulphide. Amsterdam: Excerpta Medica, 1967;219-30.

${ }^{9}$ Kubota J. Historical view of carbon disulphide poisoning in the Japanese viscose rayon industry. In: Brieger $\mathbf{H}$, Teisinger $\mathbf{J}$, eds. Toxicology of carbon disulphide. Amsterdam: Excerpta Medica, 1967:192-6.

10 Toyama T, Sakurai H. Ten-year changes in exposure level and toxicological manifestations in carbon disulphide workers. In: Brieger H, Teisinger J, eds. Toxicology of carbon disulphide. Amsterdam: Excerpta Medica, 1967: 197-204.

${ }^{11}$ Sakurai H, Toyama H. Chronic nephropathy in carbon disulfide workers. In: Proceedings of the Sixteenth International Congress on Occupational Health, Tokyo, Japan. Tokyo: 1969:578-80.

12 World Health Organisation. Environmental health criteria 10: carbon disulfide. Geneva: WHO, 1979:48, 59.

${ }^{13}$ Hernberg S, Nurminen M, Tolonen M. Excess mortality from coronary heart disease in viscose rayon workers exposed to carbon disulfide. Work Environ Health 1973;10:93-9.

${ }_{14}$ Tolonen M, Hernberg S, Nurminen M, Tiitola K. A follow-up study of coronary heart disease in viscose rayon workers exposed to carbon disulfide. $\mathrm{Br} J$ Ind $\mathrm{Med}$ $1975 ; 32: 1-10$. 
${ }^{15}$ Hernberg S, Tolonen M, Nurminen M. Eight-year followup of viscose rayon workers exposed to carbon disulfide. Scand J Work Environ Health 1976;2:27-30.

16 Tolonen M, Nurminen M, Hernberg S. Ten-year coronary mortality of workers exposed to carbon disulfide. Scand J Work Environ Health 1979;5:109-14.

${ }^{17}$ Mowé G. Coronary heart disease and occupational exposure to carbon disulfide. In: Abstracts of the second international symposium on toxicology of carbon disulfide. Yugoslavia: Banja Koviljaca, 1971:7.

18 Sakurai S. Cohort study of the hypertensive effects of carbon disulfide in viscose rayon workers. Keio $\mathrm{J} \mathrm{Med}$ $1977 ; 26: 223-33$
${ }^{19}$ Attinger E. Chronische Schwefelkohlenstoff vergiftung unter dem "scheinbar ungewöhnlichen" Bilde einer schweren Gefässkrankheit. Schweiz Med Wochenschr $1948 ; 78: 667-9$.

${ }^{20}$ Gsell O. Nephritis bei chronischer Schweflkohlenstoff- und Bleivergiftung, sowie bei Silikose. Z Unfallmed Berufskr $1948 ; 41: 55-65$.

${ }^{21}$ Attinger E. Chronische Schwefelkohlenstoff vergiftung unter dem Bilde einer schweren Gefässkrankheit. Schweiz Med Wochenschr 1952;82:829-30.

${ }^{22}$ Rechenberg HK. Das vasculäre Spätsyndrom der chronischen Schwefelkohlenstoffvergiftung. Helv Med Acta 1957;24:510-3. 